\title{
Long-acting capsid inhibitor protects macaques from repeat SHIV challenges
}

https://doi.org/10.1038/s41586-021-04279-4

Received: 2 June 2021

Accepted: 24 November 2021

Published online: 7 December 2021

\section{Open access}

Check for updates

\author{
Samuel J. Vidal ${ }^{1,2,6}$, Elena Bekerman ${ }^{3,6}$, Derek Hansen ${ }^{3}$, Bing Lu ${ }^{3}$, Kelly Wang $^{3}$, Judy Mwangi ${ }^{3}$, \\ William Rowe ${ }^{3}$, Federico Campigotto ${ }^{3}$, Jim Zheng ${ }^{3}$, Darryl Kato ${ }^{3}$, Abishek Chandrashekar', \\ Julia Barrett', Shivani Patel', Huahua Wan', Tochi Anioke', Noe B. Mercado', \\ Joseph P. Nkolola', Melissa J. Ferguson ${ }^{4}$, William J. Rinaldi ${ }^{4}$, Christian Callebaut ${ }^{3}$ \\ Wade Blair ${ }^{3}$, Tomas Cihlar ${ }^{3}$, Romas Geleziunas ${ }^{3}$, Stephen R. Yant ${ }^{3 凶}$ \& Dan H. Barouch ${ }^{1,5 凶}$
}

Because no currently available vaccine can prevent HIV infection, pre-exposure prophylaxis (PrEP) with antiretrovirals (ARVs) is an important tool for combating the HIV pandemic ${ }^{1,2}$. Long-acting ARVs promise to build on the success of current PrEP strategies, which must be taken daily, by reducing the frequency of administration ${ }^{3}$. GS-CA1 is a small-molecule HIV capsid inhibitor with picomolar antiviral potency against a broad array of HIV strains, including variants resistant to existing ARVs, and has shown long-acting therapeutic potential in a mouse model of HIV infection ${ }^{4}$. Here we show that a single subcutaneous administration of GS-CA1 provides long-term protection against repeated rectal simian-human immunodeficiency virus (SHIV) challenges in rhesus macaques. Whereas all control animals became infected after 15 weekly challenges, a single $300 \mathrm{mg} \mathrm{kg}^{-1}$ dose of GS-CA1 provided per-exposure infection risk reduction of $97 \%$ for 24 weeks. Pharmacokinetic analysis showed a correlation between GS-CA1 plasma concentration and protection from SHIV challenges. GS-CA1 levels greater than twice the rhesus plasma protein-adjusted $95 \%$ effective concentration conferred $100 \%$ protection in this model. These proof-of-concept data support the development of capsid inhibitors as a novel long-acting PrEP strategy in humans.
The HIV pandemic is a leading cause of morbidity and mortality worldwide $^{5}$. Current strategies for HIV prevention include public health measures as well as vaccine development and improved pre-exposure prophylaxis (PrEP) uptake. Studies conducted by the Centre for the AIDS Programme of Research in South Africa (CAPRISA; trial 004) ${ }^{6}$, Pre-exposure Prophylaxis Initiative (iPrEx) ${ }^{7}$ and Partners PrEP ${ }^{8}$ have shown that tenofovir-based PrEP can reduce HIV transmission. Recent real-world data confirm a significant population-level reduction in HIV-1 incidence in areas in which PrEP uptake is high ${ }^{9,10}$. However, PrEP strategies reliant on frequent drug administration are limited by adherence, which reduces their real-world impact on HIV transmission ${ }^{11-13}$. Long-acting PrEP agents may reduce the barriers associated with daily drug administration, frequent healthcare interactions and the stigma surrounding sexually transmitted infections including HIV $^{3}$. As part of this approach, a long-acting formulation of the integrase strand-transfer inhibitor cabotegravir (CAB-LA), which is injected subcutaneously every 2 months, was shown to reduce HIV transmission in an HIV Prevention Trials Network (HPTN) study (HPTN 083) ${ }^{14}$.

The HIV capsid protein has multiple essential roles in the early and late stages of the viral replication cycle, making it an attractive target for antiretrovirals (ARVs) ${ }^{15}$. Lenacapavir (LEN, formerly GS-6207) is the first clinically validated HIV capsid inhibitor and displays picomolar antiviral activity against both wild-type virus and variants resistant to current ARVs ${ }^{16}$. LEN binds at a highly conserved interface between capsid protein monomers, which causes defects in capsid nuclear import, reduced virion production and aberrant capsid assembly. A long-acting formulation of LEN has been shown to have potent antiviral activity with a maximum $2.3 \log _{10}$ decline in HIV-1RNA after 9 days of monotherapy ${ }^{17}$ and the potential for twice-yearly subcutaneous dosing in a phase $1 \mathrm{~b}$ study ${ }^{18}$. GS-CA1, a structural analogue of LEN, has the same capsid-dependent multistage mechanism of action, similar binding affinity for different forms of HIV capsid (i.e., precursor, monomer, pentamer and hexamer), similar potency against both HIV and simian immunodeficiency virus (SIV), and a similar resistance profile. In addition, it has previously been demonstrated to have high preclinical efficacy in a humanized mouse model of HIV-1 treatment (Extended Data Table 1) ${ }^{4}$. However, long-term prophylactic efficacy of LEN or GS-CA1 has not previously been demonstrated. In this study, we assess the potential of a single dose of long-acting capsid inhibitor to offer protection against repeated challenges with simian-human immunodeficiency virus (SHIV) in rhesus macaques. GS-CA1 was chosen for this analysis because of its predicted higher rate of metabolic clearance in comparison to LEN and the associated accelerated washout phase after dose administration, which enables timely evaluation of the prophylactic efficacy of this compound class over a wide range of exposures. 

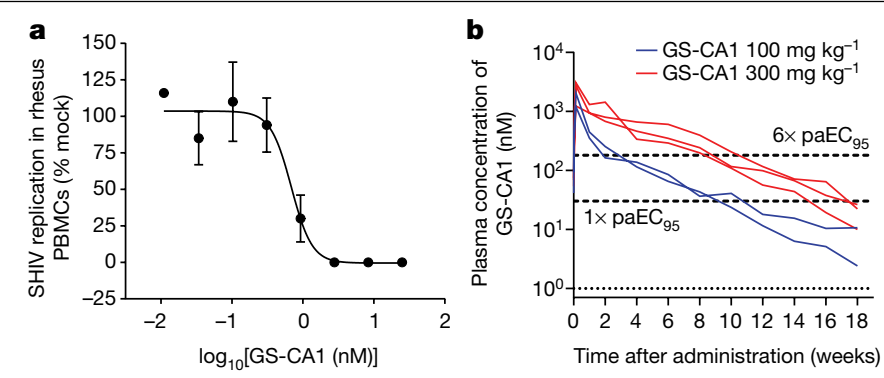

Fig. 1 GS-CA1 exhibits potent antiviral activity in vitro and long-acting pharmacokinetics in rhesus macaques. a, Representative antiviral dose-response curve for GS-CA1 in rhesus PBMCs acutely infected with SHIV-SF162P3. Data are shown as mean \pm s.d. from one of seven assays $(n=3$ biological replicates each).b, Plasma GS-CA1 levels measured by mass spectrometry following a single subcutaneous administration of GS-CA1 dosed at $300 \mathrm{~m} \mathrm{~kg} \mathrm{k}^{-1}$ in three male rhesus macaques and at $100 \mathrm{mg} \mathrm{kg}^{-1}$ in two male rhesus macaques. The bottom dotted line represents the assay limit of detection (LOD; $1 \mathrm{nM})$. The top dashed lines represent one and six times the rhesus $\mathrm{paEC}_{95}$ for GS-CA1 (30.2 $\mathrm{nM}$ and $181.2 \mathrm{nM}$, respectively).

\section{GS-CA1 inhibits SHIV in macaque cells}

GS-CA1 displayed potent in vitro anti-SHIV activity in peripheral blood mononuclear cells (PBMCs) isolated from three individual rhesus macaques of Indian origin (Macaca mulatta), with a mean 50\% effective concentration ( $\mathrm{EC}_{50}$ ) of $0.72 \mathrm{nM}$ (Fig. 1a and Extended Data Table 2). This compound also showed a mean Hill slope value of $3.0 \pm 0.7$ in high-density antiviral dose-response curves measured against the HIV-1 IIIb strain in MT-4 cells, yielding a calculated $95 \%$ effective concentration $\left(\mathrm{EC}_{95}\right.$ ) of $1.91 \mathrm{nM}$ when applied to the $\mathrm{EC}_{50}$ measured in SHIV-infected rhesus PBMCs. In vivo application showed that a large portion of the subcutaneously administered GS-CA1 became bound by plasma proteins, leaving less free drug available for antiviral effects. Competitive equilibrium dialysis was thus used to account for rhesus plasma protein binding to GS-CA1, resulting in a projected 15.8 -fold decrease in free GS-CA1 concentration in vivo and yielding a rhesus protein-adjusted $\mathrm{EC}_{95}\left(\mathrm{paEC}_{95}\right)$ value of $30.2 \mathrm{nM}$.

\section{GS-CA1 shows long-acting plasma exposure}

Low hepatic clearance is an essential attribute for a long-acting agent. Titration with ${ }^{3} \mathrm{H}$-labelled GS-CA1 was necessary to accurately measure the low turnover of GS-CA1 in primary rhesus hepatocytes and showed a predicted rate of hepatic clearance of $0.071 \mathrm{~h}^{-1} \mathrm{~kg}^{-1}$, or $2.9 \%$ of the hepatic extraction. These in vitro data suggest that GS-CA1 has the potential to sustain long-acting plasma exposure in rhesus macaques. To test this hypothesis and to select an appropriate GS-CA1 dose for the rhesus efficacy studies, we performed a pilot pharmacokinetic study with a single subcutaneous administration of a GS-CA1 formulation at two dose levels predicted to cover a broad range of plasma exposures over the projected length of the study. GS-CA1 was administered at $100 \mathrm{mg} \mathrm{kg}^{-1}$ and $300 \mathrm{mg} \mathrm{kg}^{-1}$ to two and three naive rhesus macaques of Indian origin, respectively, and its levels were monitored for 18 weeks. Plasma drug levels peaked in the concentration range of $1-3 \mu \mathrm{M}$ by day 1 after dose administration, before decreasing to $0.4-1.1 \mu \mathrm{M}$ by day 7 after dose administration. After this, GS-CA1 levels were maintained in excess of the rhesus paEC ${ }_{95}$ value for at least 8 weeks and 14 weeks and in excess of six times the rhesus $\mathrm{paEC}_{95}$ value for at least 1 week and 8 weeks for the $100 \mathrm{mg} \mathrm{kg}^{-1}$ and $300 \mathrm{mg} \mathrm{kg}^{-1}$ doses, respectively (Fig. 1b). Given that the mean target clinical exposure of LEN for HIV treatment is six times its paEC ${ }_{95}$ in humans ${ }^{18}$, GS-CA1 doses of $300 \mathrm{mg} \mathrm{kg}^{-1}$ and $150 \mathrm{mg} \mathrm{kg}^{-1}$ were selected for the repeat SHIV challenge study to assess the reduction in transmission risk across rhesus-equivalent GS-CA1 exposures in excess of, equal to and below this clinically relevant target concentration.

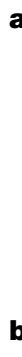

a
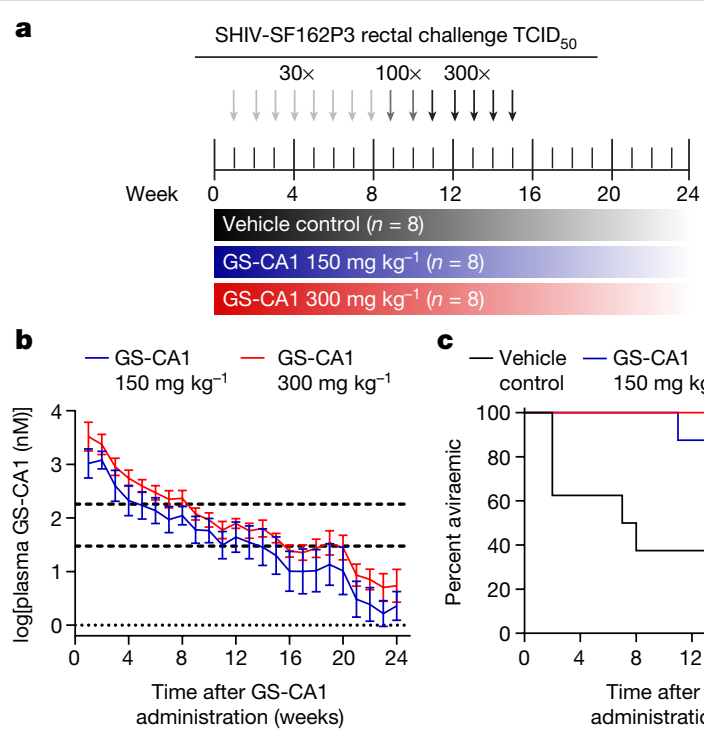

c

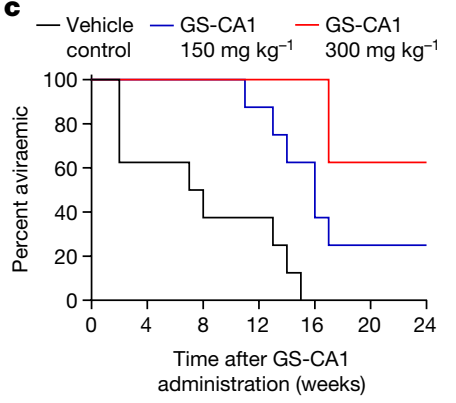

Fig. 2 | Single-dose GS-CA1 confers long-term protection from repeated rectalSHIV challenge in rhesus macaques. a, Study design. Rhesus macaques of Indian origin were treated with a single subcutaneous administration of vehicle control or GS-CA1 at week 0 followed by weekly intrarectal challenges with SHIV-SF162P3 in a dose-escalation scheme until all control animals were confirmed to be infected on week 15. b, Plasma GS-CA1 levels measured by mass spectrometry over time in rhesus macaques dosed once at $150 \mathrm{mg} \mathrm{kg}^{-1}$ or $300 \mathrm{mg} \mathrm{kg}^{-1}$. The data for each group are shown as mean \pm s.d. from eight rhesus macaques. The bottom dotted line represents the assay LOD $(1 \mathrm{nM})$. The top dashed lines represent one and six times the rhesus $\mathrm{paEC}_{95}$ for GS-CA1 (30.2 nM and 181.2 nM, respectively).c, Kaplan-Meier plots showing the development of viraemia as assessed by RT-qPCR for plasma SHIV gag among rhesus macaques treated with a single subcutaneous administration of vehicle control $(n=8)$, GS-CA1 dosed at $150 \mathrm{mg} \mathrm{kg}^{-1}(n=8)$ or GS-CA1 dosed at $300 \mathrm{mg} \mathrm{kg}^{-1}(n=8)$.

\section{GS-CA1 provides protection from SHIV challenges}

We next conducted a study to evaluate the protective efficacy of a single administration of GS-CA1 against repeated, escalating-dose rectal SHIV-SF162P3 challenges in rhesus macaques (Fig. 2a). For this challenge study, 24 rhesus macaques of Indian origin were divided into 3 groups of 8 monkeys each with balanced sex and weight distributions. All animals received a single subcutaneous administration at week 0 in the scapular region. Animals in group 1 received the vehicle control, whereas those in groups 2 and 3 received GS-CA1 doses of $150 \mathrm{mg} \mathrm{kg}^{-1}$ and $300 \mathrm{mg} \mathrm{kg}^{-1}$, respectively. Consistent with the pilot study, a single administration of GS-CA1 at both $150 \mathrm{mg} \mathrm{kg}^{-1}$ and $300 \mathrm{mg} \mathrm{kg}^{-1}$ achieved long-acting exposure. Specifically, peaks were reached at plasma GS-CA1 concentrations of $3.0 \mu \mathrm{M}$ and $5.5 \mu \mathrm{M}$ approximately $24 \mathrm{~h}$ and $42 \mathrm{~h}$ after dose administration, respectively, and GS-CA1 levels decreased slowly thereafter with a mean half-life of 287-317 h (Fig. 2b and Extended Data Table 3). The group receiving a dose of $300 \mathrm{mg} \mathrm{kg}^{-1}$ remained above the rhesus $\mathrm{paEC}_{95}$ and six times above the rhesus $\mathrm{paEC}_{95}$ for 14-16 weeks and 5-8 weeks, respectively, whereas the group receiving a dose of $150 \mathrm{mg} \mathrm{kg}^{-1}$ remained above these target concentrations for 8-15 weeks and 3-7 weeks, respectively. The variance in GS-CA1 pharmacokinetic parameters across animals was comparable to that observed with $900 \mathrm{mg}$ of LEN in humans ${ }^{18}$, whereas the half-life and length of exposure above the corresponding $6 \times \mathrm{paEC}_{95}$ threshold were lower than expected.

To define the protective efficacy of GS-CA1, all animals received 15 weekly intrarectal SHIV-SF162P3 challenges in a dose-escalation protocol beginning at week 1 following GS-CA1 administration. Infection was assessed by quantifying viral gag RNA levels in the plasma by 
Table 1 | Statistical analysis of the rhesus macaque challenge study

\begin{tabular}{|c|c|c|c|c|}
\hline & $\begin{array}{l}\text { Proportion } \\
\text { of animals } \\
\text { protected }\end{array}$ & $\begin{array}{l}\text { Median weeks } \\
\text { to viraemia } \\
(95 \% \mathrm{CI})\end{array}$ & $\begin{array}{l}\text { Hazard ratio ( } 95 \% \\
\mathrm{Cl}) / \text { per-exposure risk } \\
\text { reduction }\end{array}$ & $P$ value \\
\hline Vehicle control & $0 / 8$ & $7.5(2,14)$ & 1 & - \\
\hline $\begin{array}{l}\text { GS-CA1, } \\
150 \mathrm{mg} \mathrm{kg}^{-1}\end{array}$ & $2 / 8$ & $16(11,-)$ & $0.127(0.03-0.51) / 87 \%$ & 0.0038 \\
\hline $\begin{array}{l}\text { GS-CA1, } \\
300 \mathrm{mg} \mathrm{kg}^{-1}\end{array}$ & $5 / 8$ & $\begin{array}{l}\text { Not reached } \\
(17,-)\end{array}$ & $\begin{array}{l}0.033(0.0059- \\
0.188) / 97 \%\end{array}$ & 0.0001 \\
\hline
\end{tabular}

Proportion of animals protected, median time (in weeks) to viraemia, estimated hazard ratios from the Cox proportional hazard model and corresponding $P$ values comparing animals receiving vehicle control and GS-CA1 are shown. $\mathrm{Cl}$, confidence interval.

quantitative PCR with reverse transcription (RT-qPCR). To define the drug levels required for protection, we monitored plasma viraemia up to week 24 as GS-CA1 levels declined below therapeutic concentrations. Eight weekly intrarectal challenges at 30 times the median tissue culture infectious dose $\left(\mathrm{TCID}_{50}\right)$ resulted in infection of five of the eight vehicle-treated animals (Fig. 2c, Table 1 and Extended Data Fig. 1). Viral challenge dose escalation to $100 \mathrm{TCID}_{50}$ for 2 weeks yielded no additional infections, whereas further escalation to $300 \mathrm{TCID}_{50}$ resulted in infection of the remaining three control animals by week 15 .

In contrast to the vehicle-treated group, the group receiving $300 \mathrm{mg} \mathrm{kg}^{-1} \mathrm{GS}-\mathrm{CA} 1$ showed no viraemia until week 17 with this escalating-dose challenge protocol, when three of the eight monkeys became SHIV positive (Fig. 2c, Table 1 and Extended Data Fig. 1). The other five monkeys remained aviraemic until the end of the study, which translates to a $97 \%$ per-exposure risk reduction with the $300 \mathrm{mg} \mathrm{kg}^{-1}$ dose $(P=0.0001$, Cox proportional hazard regression analysis). The group that received a single administration of GS-CA1 at the reduced dose of $150 \mathrm{mg} \mathrm{kg}^{-1}$ also exhibited fewer and delayed infections relative to the vehicle-treated control group. Specifically, no viraemia was detected until week 11, and two of the eight monkeys remained aviraemic until the end of the study, which represents an $87 \%$ per-exposure risk reduction $(P=0.0038)$. The median time to viraemia was 7.5 weeks in the vehicle-treated group and 16 weeks in the group receiving $150 \mathrm{mg} \mathrm{kg}^{-1} \mathrm{GS}-\mathrm{CA1}$; this point was not reached in the group receiving $300 \mathrm{mg} \mathrm{kg}^{-1} \mathrm{GS}-\mathrm{CA} 1$ owing to an insufficient number of infections. The peak viral loads were significantly lower and the viral loads measured 7 weeks after infection showed a trend towards lower levels among the GS-CA1-treated animals as compared with the vehicle-treated control animals. This result could reflect a residual antiviral effect from subtherapeutic inhibitor levels (Extended Data Fig. 2).

We next performed immunological analyses in the GS-CA1-treated rhesus monkeys. First, we assessed the development of humoral immune responses against the SHIV envelope (Env) glycoprotein by enzyme-linked immunosorbent assay (ELISA). We detected binding antibody responses to Env at week 24 in all animals with SHIV viraemia but none in those without SHIV viraemia (Extended Data Fig. 3a). Second, we assessed the development of cellular immune responses against SHIV Gag polyprotein by enzyme-linked immune absorbent spot (ELISPOT) assay. We detected T cell responses to the Gag protein at week 19 in all but one animal with SHIV viraemia and in none of the animals without SHIV viraemia (Extended Data Fig. 3b). These immunologic data suggest that the GS-CA1-treated animals that remained aviraemic during the study period were in fact protected from SHIV challenge.

Finally, we performed additional studies to confirm that our plasma viraemia measurements provided early detection of initial infection in the setting of GS-CA1 prophylaxis.

First, we performed intact proviral DNA analysis (IPDA) to detect integrated SHIV in a subset of infected animals treated with vehicle control or GS-CA1 with available PBMCs. Intact SHIV proviruses became detectable at the same time points at which plasma viraemia was detected in all cases except for a single GS-CA1-treated animal (K394) that showed very low-level intact provirus 1 week before detection of viraemia (Extended Data Table 4). Second, we determined the EnvELISA seroconversion time points for all infected animals and observed that viraemia preceded seroconversion in all cases (Extended Data Table 5). The median time to seroconversion from the onset of viraemia was 2.5 weeks (range, 1 to 13 weeks) in vehicle-treated control animals and 4 weeks (range, 1 to 5 weeks) in GS-CA1-treated animals, although the difference between the groups was not significant $(P=0.80$, Mann-Whitney $U$ test $)$.

\section{Protective levels of GS-CA1 in macaques}

We next investigated the relationship between GS-CA1 plasma concentrations and protection against SHIV challenge. To facilitate exposure comparisons with other antivirals including LEN, we converted the concentrations for GS-CA1 to multiples of its rhesus $\mathrm{paEC}_{95}$. To estimate the protective levels for GS-CA1, we focused on six animals that developed viraemia in the group receiving a dose of $150 \mathrm{mg} \mathrm{kg}^{-1}$ and three animals that developed viraemia in the group receiving a dose of $300 \mathrm{mg} \mathrm{kg}^{-1}$. Assuming a 2-week delay between rectal SHIV infection and detectable peripheral blood viraemia, we averaged the GS-CA1 exposure values 2 weeks before the first detectable viraemia among the infected animals. We estimated that mucosal infection occurred in the presence of $31.4 \mathrm{nM} \mathrm{GS}-\mathrm{CA} 1$ on average, which is equal to the concentration of rhesus paEC $_{95}$ at a multiple of 1.0 (range, 0.4-1.6; Fig. 3a, b). Therefore, we estimated that, overall, all animals were fully protected in this model when the GS-CA1 plasma concentrations were more than twice the rhesus $\mathrm{paEC}_{95}$ value for GS-CA1.

\section{Plasma virus resistance analysis}

To evaluate potential development of resistance against GS-CA1, particularly during the washout phase, we conducted longitudinal population-level sequence analysis of the SHIV gag region encoding capsid in rhesus plasma (Extended Data Fig. 4). As expected, plasma virus obtained from placebo-treated control animals encoded only wild-type capsid protein. Of the plasma virus samples analysed from the nine viraemic animals dosed with GS-CA1, 34 of 35 (97\%) produced high-quality sequence reads, with wild-type capsid detected in all nine animals at the end of the study. Animal K342 in the low-dose $\left(150 \mathrm{mg} \mathrm{kg}^{-1}\right.$ GS-CA1) group showed transient prevalence of a capsid variant with substitution to alanine at Val11 (V11A; the numbering used here follows the HIV-1HXB2 reference sequence) between study weeks 13 and 21 . This V11A substitution, which is located far outside the GS-CA1-binding site in the capsid, disappeared by week 22 in this animal and is not associated with GS-CA1 resistance 4 . Thus, no study animal showed emergence of variants associated with GS-CA1 resistance for the duration of this 24-week efficacy study.

\section{Discussion}

Long-acting PrEP regimens might overcome some of the current barriers to PrEP implementation, including the need for daily administration and frequent healthcare interaction. The HPTN 083 study recently demonstrated that long-acting ARV monotherapy agents such as CAB-LA can effectively reduce the rate of HIV-1 acquisition ${ }^{14}$. In the present study, we investigated whether a single administration of the capsid inhibitor GS-CA1 could provide long-term protection from repeated SHIV challenges in rhesus macaques. GS-CA1 provided significant protection from rectal infection after 15 repeat challenges, with complete protection achieved when GS-CA1 levels were more than twice the rhesus paEC $_{95}$.

Given the similar structural, mechanistic and long-acting properties of GS-CA1 and LEN, the preclinical GS-CA1 data in this study may inform the clinical development of LEN for PrEP. Our data show protection against rectal SHIV acquisition in macaques at plasma GS-CA1 exposures more than twice the rhesus $\mathrm{paEC}_{95}$, which suggests that the 


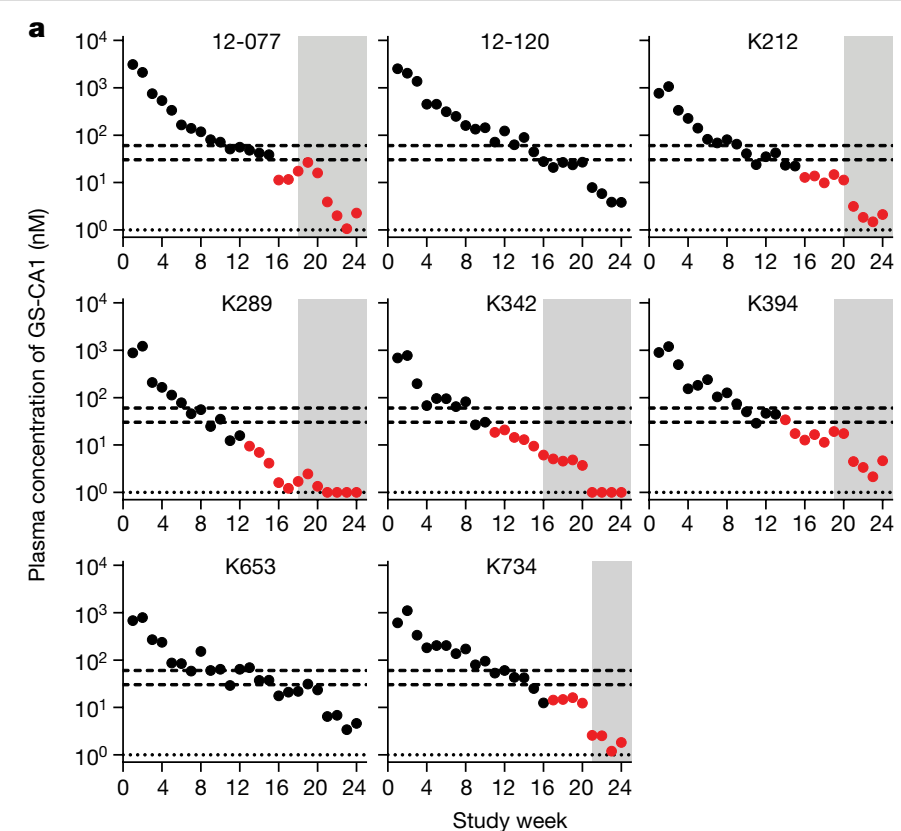

Fig. 3 | Association between plasma GS-CA1 and protection from SHIV challenge. a, Plasma levels of GS-CA1 measured by mass spectrometry among individual rhesus macaques $(n=8)$ treated with a $150 \mathrm{mg} \mathrm{kg}^{-1}$ dose over time. Black circles represent time points before the first detection of viraemia. Red circles represent time points including and after the first detection of viraemia. Grey shaded boxes represent serum Env ELISA seroconversion time points.

current clinical formulation of LEN, conferring a mean exposure of more than six times human $\mathrm{paEC}_{95}$ for at least 6 months after a single subcutaneous dose, might be sufficient for PrEP in humans. Nonetheless, the exposure threshold for prophylaxis against HIV acquisition with LEN in humans cannot be directly inferred from this escalating-dose preclinical study and will need to be defined in adequately powered clinical studies. Moreover, animal studies may underestimate exposures required for protection, as evident from the 4 of 12 incident infections among 2,243 analysed participants in the HPTN 083 study that occurred even though the target CAB-LA exposures were predicted preclinically to be efficacious ${ }^{19,20}$. In future work, it will be important to evaluate the efficacy of long-acting capsid inhibitors by other routes of transmission (e.g., vaginal) to establish broader relevance to the populations at risk. Furthermore, a study incorporating mucosal biopsies could establish the pharmacokinetic relationship between plasma and tissue levels of GS-CA1 at the sites of infection.

The emergence of resistance mutations may be an important consideration during the implementation of any single-agent long-acting PrEP strategy. In the phase 3 HPTN 083 trial, 16 HIV seroconversions occurred among participants randomized to CAB-LA, including 4 baseline infections ${ }^{20}$. Genotyping in 14 of these 16 cases revealed integrase mutations among 5 participants, although no resistance was observed among infections presumed to have occurred during the pharmacokinetic tail. Our preclinical study revealed no resistance mutations in the capsid protein among nine rhesus macaques that were treated with GS-CA1 and became infected. However, the low-level resistance mutation $\mathrm{Q} 67 \mathrm{H}$ in capsid (conferring a sixfold decrease in susceptibility to $\mathrm{LEN}^{16}$ ) was detected in 2 of 29 participants randomized to long-acting LEN monotherapy in a recent phase $1 \mathrm{~b}$ study ${ }^{21}$. This mutation was detected 9 days after dose administration in at least one study participant in two of the LEN treatment arms among the five total receiving the lowest doses $(20 \mathrm{mg}$ and $50 \mathrm{mg}$ ) when the average LEN plasma concentrations measured 0.7 and 1.1 times the human $\mathrm{paEC}_{95}$, respectively; both concentrations are considered to be subtherapeutic for HIV-1 treatment. These data suggest that

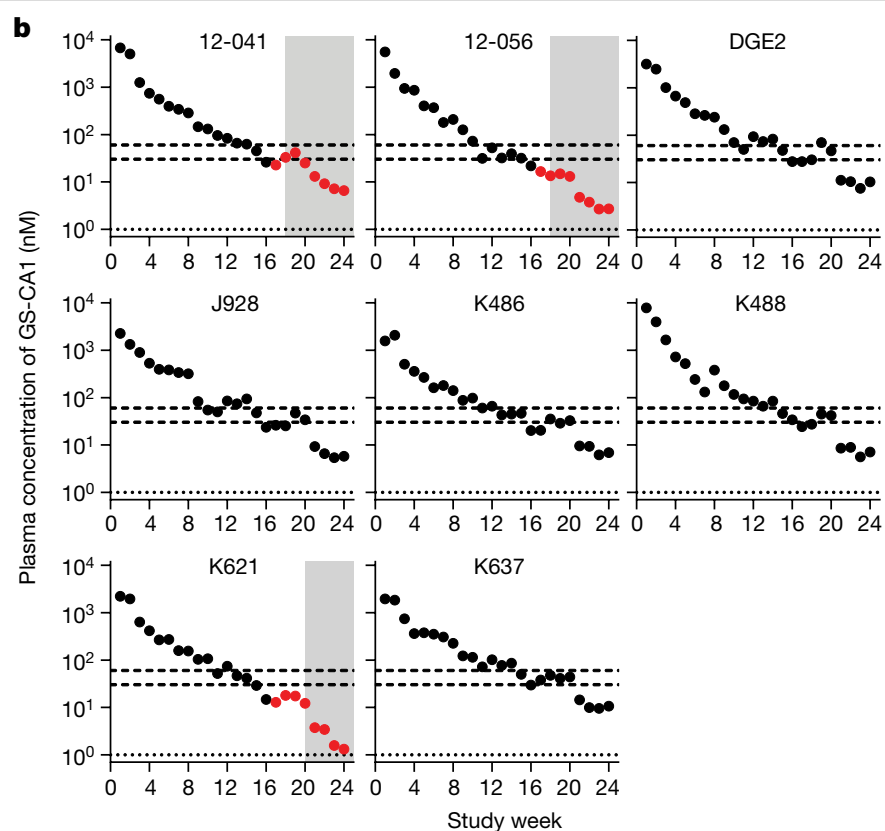

The bottom dotted line represents the assay LOD $(1 \mathrm{nM})$. The bottom and top dashed lines represent one and two times the rhesus paEC ${ }_{95}$, respectively. b, Same data as in a for rhesus macaques treated with GS-CA1 at a dose of $300 \mathrm{mg} \mathrm{kg}^{-1}$. No signal above the assay LOD was observed among the eight placebo-treated control animals throughout the study.

large clinical studies will likely be necessary to fully characterize the potential emergence of resistance mutations among long-acting PrEP recipients.

In summary, our data demonstrate that a single subcutaneous administration of the capsid inhibitor GS-CA1 provides long-term protection against SHIV infection in rhesus macaques. Together with recent studies showing the potency and pharmacokinetics of LEN in people living with HIV, these data suggest that long-acting capsid inhibitors might offer an important and novel strategy for HIV prevention. A phase 3 clinical study to assess the safety and effectiveness of LEN for HIV PrEP has therefore been initiated (NCT04925752).

\section{Online content}

Any methods, additional references, Nature Research reporting summaries, source data, extended data, supplementary information, acknowledgements, peer review information; details of author contributions and competing interests; and statements of data and code availability are available at https://doi.org/10.1038/s41586-021-04279-4.

1. World Health Organization. Consolidated Guidelines on the Use of Antiretroviral Drugs for Treating and Preventing HIV Infection: Recommendations for a Public Health Approach, 2nd ed. (World Health Organization Press, 2016).

2. Fonner, V. A. et al. Effectiveness and safety of oral HIV preexposure prophylaxis for all populations. AIDS 30, 1973-1983 (2016).

3. Coelho, L. E., Torres, T. S., Veloso, V. G., Landovitz, R. J. \& Grinsztejn, B. Pre-exposure prophylaxis 2.0: new drugs and technologies in the pipeline. Lancet HIV 6, e788-e799 (2019).

4. Yant, S. R. et al. A highly potent long-acting small-molecule HIV-1 capsid inhibitor with efficacy in a humanized mouse model. Nat. Med. 25, 1377-1384 (2019).

5. GBD 2019 Diseases and Injuries Collaborators. Global burden of 369 diseases and injuries in 204 countries and territories, 1990-2019: a systematic analysis for the Global Burden of Disease Study 2019. Lancet 396, 1204-1222 (2020).

6. Abdool Karim, Q. et al. Effectiveness and safety of tenofovir gel, an antiretroviral microbicide, for the prevention of HIV infection in women. Science 329, 1168-1174 (2010).

7. Grant, R. M. et al. Preexposure chemoprophylaxis for HIV prevention in men who have sex with men. N. Engl. J. Med. 363, 2587-2599 (2010).

8. Baeten, J. M. et al. Antiretroviral prophylaxis for HIV prevention in heterosexual men and women. N. Engl. J. Med. 367, 399-410 (2012). 


\section{Article}

9. Grulich, A. E. et al. Population-level effectiveness of rapid, targeted, high-coverage roll-out of HIV pre-exposure prophylaxis in men who have sex with men: the EPIC-NSW prospective cohort study. Lancet HIV 5, e629-e637 (2018).

10. Sullivan, P. S. et al. The impact of pre-exposure prophylaxis with FTC/TDF on HIV diagnoses, 2012-2016. Presented at the 22nd International AIDS Conference, Amsterdam, the Netherlands, 23-27 July 2018 (2018)

11. Anderson, P. L. et al. Emtricitabine-tenofovir concentrations and pre-exposure prophylaxis efficacy in men who have sex with men. Sci. Transl. Med. 4, 151ra125 (2012).

12. Van Damme, L. et al. Preexposure prophylaxis for HIV infection among African women N. Engl. J. Med. 367, 411-422 (2012).

13. Marrazzo, J. M. et al. Tenofovir-based preexposure prophylaxis for HIV infection among African women. N. Engl. J. Med. 372, 509-518 (2015).

14. Landovitz, R. J. et al. Cabotegravir for HIV prevention in cisgender men and transgender women. N. Engl. J. Med. 385, 595-608 (2021).

15. Carnes, S. K., Sheehan, J. H. \& Aiken, C. Inhibitors of the HIV-1 capsid, a target of opportunity. Curr. Opin. HIV AIDS 13, 359-365 (2018).

16. Link, J. O. et al. Clinical targeting of HIV capsid protein with a long-acting small molecule. Nature 584, 614-618 (2020).

17. Daar, E. et al. Dose-response relationship of subcutaneous long-acting HIV capsid inhibitor GS-6207. Presented at the 27th Conference on Retroviruses and Opportunistic Infections, Boston, MA, 8-11 March 2020 (2020).

18. Begley, R. et al. Lenacapavir sustained delivery formulation supports 6-month dosing interval. Presented at AIDS 2020: 23rd International AIDS Conference, virtual, 6-10 July 2020 (2020).
19. Andrews, C. D. et al. Long-acting integrase inhibitor protects macaques from intrarectal simian/human immunodeficiency virus. Science 343, 1151-1154 (2014).

20. Marzinke, M. A. et al. Characterization of HIV infection in cisgender men and transgende women who have sex with men receiving injectable cabotegravir for HIV prevention: HPTN 083. J. Infect. Dis. https://doi.org/10.1093/infdis/jiab152 (2021).

21. Margot, N. et al. Lenacapavir resistance analysis in a phase $1 \mathrm{~b}$ clinical proof-of-concept study. Paper presented at 2020 HIV Drug Therapy Glasgow, virtual, 5-8 October 2020 (2020).

Publisher's note Springer Nature remains neutral with regard to jurisdictional claims in published maps and institutional affiliations.

Open Access This article is licensed under a Creative Commons Attribution 4.0 International License, which permits use, sharing, adaptation, distribution and reproduction in any medium or format, as long as you give appropriate credit to the original author(s) and the source, provide a link to the Creative Commons license, and indicate if changes were made. The images or other third party material in this article are included in the article's Creative Commons license, unless indicated otherwise in a credit line to the material. If material is not included in the article's Creative Commons license and your intended use is not permitted by statutory regulation or exceeds the permitted use, you will need to obtain permission directly from the copyright holder. To view a copy of this license, visit http://creativecommons.org/licenses/by/4.0/.

(c) The Author(s) 2021 


\section{Methods}

\section{Drug and formulation}

GS-CA1 and a generic internal small-molecule standard used for liquid chromatography coupled with mass spectrometry (LC-MS) experiments were both synthesized at Gilead Sciences and were subjected to standard quality control analysis. For the animal dosing studies, GS-CA1 was dissolved in vehicle (58.03\% PEG 300, 27.1\% water, 6.78\% ethanol, $6.61 \%$ poloxamer $188,1.48 \%$ sodium hydroxide) at $300 \mathrm{mg} \mathrm{ml}^{-1}$, producing a clear, yellow-orange solution. The solution was stored at ambient temperature protected from light until dosing.

\section{Metabolic stability of $\left[{ }^{3} \mathbf{H}\right] \mathrm{GS}-\mathrm{CA} 1$ in primary rhesus hepatocytes} A 500- $\mu$ l suspension of human hepatocytes $\left(1 \times 10^{6}\right.$ cells per $\left.\mathrm{ml}\right)$ and $0.25 \mu \mathrm{M}\left[{ }^{3} \mathrm{H}\right] \mathrm{GS}$-CA1 was prepared in Krebs-Henseleit buffer (KHB) medium and was incubated in a humidified incubator at $37^{\circ} \mathrm{C}$ with $5 \% \mathrm{CO}_{2}$ in duplicate wells of a 24 -well plate. Propranolol $(1 \mu \mathrm{M}$ final), a compound known to be efficiently metabolized by hepatocytes by oxidation and conjugation, was used as a positive control. A cell-free control was incubated in parallel as a negative control. Aliquots $(100 \mu \mathrm{l})$ were removed after $0 \mathrm{~h}, 1 \mathrm{~h}, 3 \mathrm{~h}$ and $6 \mathrm{~h}$ and were then mixed with $200 \mu$ l quenching solution, placed on a shaker for $10 \mathrm{~min}$ and centrifuged at $3,000 \mathrm{~g}$ for $60 \mathrm{~min}$. The supernatant was transferred to a new plate, diluted with $100 \mu \mathrm{l}$ water and placed on a shaker for $10 \mathrm{~min}$. Quantification of $\left[{ }^{3} \mathrm{H}\right] \mathrm{GS}$-CA1 and its metabolites was performed by radio flow chromatography using a PerkinElmer Radiomatic 625TR flow scintillation analyser with a 500- $\mu$ l flow cell coupled to a Dionex Ultimate 3000 high-performance liquid chromatography (HPLC) system. PerkinElmer Ultima-Flo was used as the scintillation cocktail, which was mixed with the HPLC effluent at a ratio of 1:1. Sample $(100 \mu \mathrm{l})$ was injected using a Leap Technologies CTC PAL autosampler. Separation was achieved on a Phenomenex Synergi Fusion-RP $80-\AA ̊$ pore size, $4-\mu \mathrm{m}$ particle size, $150 \times 4.6-\mathrm{mm}$ column maintained at $32{ }^{\circ} \mathrm{C}$. Mobile phase A consisted of $95 \%$ water, $5 \%$ acetonitrile and $0.1 \%$ trifluoroacetic acid (TFA). Mobile phase B consisted of $95 \%$ acetonitrile, $5 \%$ water and $0.1 \%$ TFA. Elution was achieved at a flow rate of $1 \mathrm{ml} \mathrm{min} \mathrm{m}^{-1}$ by linear gradients: the initial condition was $2 \%$ B at 0 min, which was increased to $75 \%$ B over $45 \mathrm{~min}$, held for $4 \mathrm{~min}$ at $75 \% \mathrm{~B}$ and then returned to the initial conditions. The column was allowed to re-equilibrate for 12 min between injections. Quantification was based on the radiochromatographic peak area using Dionex (Thermo Scientific) Chromeleon 6.8 software.

\section{Cell culture}

Freshly isolated PBMCs from three male rhesus macaque (M. mulatta) donors of Indian origin (HumanCells Biosciences) were cultured in RPMI- 1640 cell culture medium (Life Technologies) supplemented with

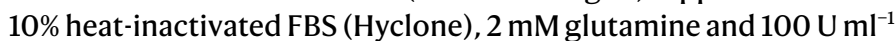
penicillin plus $100 \mathrm{\mu g} \mathrm{ml}^{-1}$ streptomycin (complete RPMI). Before their use in the antiviral assays, rhesus PBMCs from three independent donors were pooled and activated at a density of $3 \times 10^{6}$ cells per $\mathrm{ml}$ for $72 \mathrm{~h}$ at $37^{\circ} \mathrm{C}$ by the addition of $1 \mu \mathrm{g} \mathrm{ml} \mathrm{I}^{-1}$ phytohemagglutinin (PHA, Sigma-Aldrich) and $50 \mathrm{U} \mathrm{ml}^{-1}$ recombinant human interleukin-2 (IL-2) (Roche Diagnostics).

\section{Anti-SHIV antiviral assay in rhesus PBMCs}

PHA/IL-2-stimulated rhesus PBMCs were infected in bulk culture with SHIV-SF162P3 at a concentration of $130 \mathrm{pg}$ of $\mathrm{p} 27$ equivalent per million PBMCs. The cells were maintained in suspension by gently rocking the cultures mixed with virus inoculum for $3 \mathrm{~h}$ at $37^{\circ} \mathrm{C}$. The cells were then pelleted by centrifugation at $500 \mathrm{~g}$ for $5 \mathrm{~min}$, washed twice with complete RPMI to remove any unadsorbed virus and seeded into 96-well plates at a cell density of $2 \times 10^{5}$ cells per well in $100 \mu$ l. Eight-point threefold serial dilutions of GS-CA1 were made in complete RPMI containing $50 \mathrm{U} \mathrm{ml}^{-1} \mathrm{IL}-2$ and were added in triplicate to wells containing cells $(100 \mu$ l per well). The cultures were incubated in a $5 \% \mathrm{CO}_{2}$ incubator at $37^{\circ} \mathrm{C}$ for 7 days. Cell-free supernatants derived from the PBMC cultures were harvested 7 days after infection, the amount of SHIV present was quantified using an SIV p27 antigen-capture ELISA assay (5436, Advanced Bioscience Laboratories) performed according to the manufacturer's protocol, and the data were acquired using SoftMax Pro 6.3.1 software (Molecular Devices). The mean $\mathrm{EC}_{50}$ value for GS-CA1, which was determined from a total of seven assays performed in triplicate, was calculated from the doseresponse curves using XLfit 5.5.0.5 software (IDBS) and was expressed graphically using GraphPad Prism 8.1.2 software. The Hill coefficient $(n)$ for GS-CA1 was measured from the slope of the dose-response curves $(n=3.03 \pm 0.69)$ and was used to derive the $\mathrm{EC}_{95}$ value using the following equation: $\mathrm{EC}_{95}=\mathrm{EC}_{50} \times(95 / 5)^{1 / n}$.

\section{Equilibrium dialysis shift assay}

Rhesus plasma protein binding to GS-CA1 was determined by competitive equilibrium dialysis. Rhesus plasma (10\%) was spiked with GS-CA1 $(2 \mu \mathrm{M})$, and this mixture and blank RPMI cell culture medium containing $10 \%$ FBS (CCM) were placed into opposite sides of assembled dialysis cells; afterwards, incubations were performed in triplicate. After a 24-h equilibration period at $37^{\circ} \mathrm{C}$, samples were quenched with 4 volumes of $90 \%(\mathrm{vol} / \mathrm{vol})$ acetonitrile and $10 \%$ (vol/vol) methanol containing internal standard. Then, they were quantified using the AB Sciex API 4000 LC-MS/MS system (GenTech Scientific) with electrospray ionization in positive mode and multiple-reaction monitoring and were analysed using Analyst 1.6.1 software. The fold change value in $100 \%$ rhesus plasma was then calculated using the plasma/CCM ratio after correcting for the sample dilution factor and the percentage of free fraction in the matrix. This shift value was multiplied by the calculated anti-SHIV $\mathrm{EC}_{95}$ value for GS-CA1 to derive the corresponding rhesus plasma paEC 95 .

\section{Animals, drug administration and viral stocks}

Studies involving the evaluation of GS-CA1 pharmacokinetics in naive male rhesus macaques of Indian origin were conducted at Covance Laboratories in a Laboratory Animal Care-accredited facility and were performed in strict compliance with all relevant ethical regulations. All study protocols were reviewed and approved by the Covance Laboratories Institutional Animal Care and Use Committee (IACUC). On day 0 of the study, rhesus monkeys were administered GS-CA1 dosed at $100 \mathrm{mg} \mathrm{kg}^{-1}(n=2)$ or $300 \mathrm{mg} \mathrm{kg}^{-1}(n=3)$ in the scapular region by subcutaneous injection using a syringe equipped with a 22-gauge needle. The GS-CA1 was prepared in a stock solution of $300 \mathrm{mg} \mathrm{ml}^{-1}$; a maximum of $2 \mathrm{ml}$ of the solution was injected into a single subcutaneous site. Whole blood was collected from each animal at designated time points, processed into plasma and then stored frozen at $-80^{\circ} \mathrm{C}$ for bioanalysis of GS-CA1 levels.

For the challenge study, 24 outbred rhesus macaques of Indian origin were assigned to the three study groups with even sex and weight distributions. All animals were housed at Alpha Genesis (Yemassee, SC), and all procedures were conducted in compliance with all relevant local, state and federal regulations and were approved by the Alpha Genesis IACUC. On week 0 , the three groups were administered vehicle control, GS-CA1 dosed at $300 \mathrm{mg} \mathrm{kg}^{-1}$ or GS-CA1 dosed at $150 \mathrm{mg} \mathrm{kg}^{-1}$ in the scapular region by subcutaneous injection using a syringe equipped with a 22-gauge needle. The GS-CA1 was prepared in a stock solution of $300 \mathrm{mg} \mathrm{ml}^{-1}$; a maximum of $2 \mathrm{ml}$ of solution was injected into a single subcutaneous site. The injection sites were monitored daily by veterinary staff for 3 days. Beginning in week 1 , animals in all three groups were challenged by the intrarectal route with $1 \mathrm{ml}$ of RPMI containing the specified dilution of a $3.62 \times 10^{3} \mathrm{TCID}_{50}$ SHIV-SF162P3 stock. At each respective time point, the challenges were performed on the same day, using the same virus stock and inoculation method across the three groups. Whole blood was collected and processed 
into plasma and PBMCs as necessary to assess routine haematology, clinical chemistry, viral load and serology as well as for bioanalysis of drug levels. The animals were considered to be protected if they remained SHIV negative by plasma PCR assay and seronegative by enzyme immunoassay throughout the 15 -week challenge phase and the 9-week follow-up.

\section{Bioanalysis of GS-CA1 in macaque plasma}

Rhesus plasma samples were stored frozen at $-80^{\circ} \mathrm{C}$. For analysis, the samples were thawed, and a 50- $\mu$ l aliquot of each sample was treated with $200 \mu$ l acetonitrile containing a generic internal small-molecule standard. After precipitation of the protein component, a $100-\mu$ laliquot of the supernatant was transferred to a clean 96-well plate and was mixed with $200 \mu \mathrm{l}$ water. A $20-\mu \mathrm{l}$ aliquot of the above solution was then injected into a Q-Exactive high-resolution mass spectrometer (Thermo Scientific) with electrospray ionization in positive mode. Quantification was performed with a Thermo Scientific Xcalibur 4.0.27.19 using accurate masses $\left(<5\right.$ parts per million mass error; $[\mathrm{M}+\mathrm{H}]^{+}$of 958.1853 for GC-CA1 and 758.3270 for the internal standard, respectively $)^{22,23}$. The lower and upper limits of quantification for GS-CA1 were $1 \mathrm{nM}$ and $10,000 \mathrm{nM}$, respectively. Pharmacokinetic parameters, including the area under the plasma concentration-time curve from time 0 to the last quantifiable time point $\left(\mathrm{AUC}_{\text {last }}\right)$, the area under the plasma concentration-time curve from time 0 to infinity $\left(\mathrm{AUC}_{\mathrm{inf}}\right)$, the maximum concentration $\left(C_{\max }\right)$, the time to reach the observed peak plasma concentration $\left(t_{\max }\right)$ and the terminal half-life $\left(t_{1 / 2}\right)$, were determined by non-compartmental analysis using Phoenix WinNonlin 6.4 build 8.1.0.3530 software (Pharsight).

\section{Plasma viral load assay}

RNA was extracted from rhesus macaque plasma using a QIAcube high-throughput instrument and an IndiSpin QIAcube HT Pathogen kit (Qiagen). RNA standards using the SIV gag sequence were generated by AmpliCap-Max T7 High-Yield Message Maker kit (Cell Script) and were purified using an RNA Clean and Concentrator kit (Zymo Research). Log dilutions of the RNA were included with each RT-qPCR assay. Reverse transcription of standards and samples was performed using a Superscript III VILO kit (Invitrogen). qPCR was performed using forward primer 5'-GTCTGCGTCATCTGGTGCATTC-3', reverse primer 5'-CACTAGGTGTCTCTGCACTATCTGTTTTG-3' and fluorescently labelled primer 5'-CTTCCTCAGTGTGTTTCACTTTCTCTTCTGCG-3' on a Quantstudio 6 Flex system (Applied Biosystems). The assay LOD was 200 copies gag per $\mathrm{ml}$.

\section{ELISA}

Rhesus serum binding antibody titres against gp140 trimers were determined by ELISA. Ninety-six-well Maxisorp ELISA plates (Thermo Fisher Scientific) were coated overnight with $100 \mu$ l per well of $1 \mu \mathrm{g} \mathrm{ml}^{-1}$ mosaic $\mathrm{M}$ gp140 protein in PBS and were then blocked for $2 \mathrm{~h}$ with blocker casein in PBS (Thermo Scientific). Macaque sera were added in threefold serial dilutions and were incubated for $1 \mathrm{~h}$ at room temperature. The plates were washed three times with PBS containing 0.05\% Tween-20 and were then incubated for $1 \mathrm{~h}$ with a 1:1,000 dilution of a horseradish peroxidase (HRP)-conjugated goat anti-human secondary antibody (Jackson ImmunoResearch Laboratories). The plates were then washed three times with the above wash buffer and were developed using SureBlue tetramethylbenzidine (TMB) microwell peroxidase (KPL). Development was stopped by the addition of a stop solution (KPL), and the plates were then analysed at $450 \mathrm{~nm}$ with a Versamax ELISA microplate reader (Molecular Devices) using Softmax Pro 6.5.1 software. The ELISA endpoint titres were defined as the highest reciprocal serum dilution that yielded an $\mathrm{OD}_{450 \mathrm{~nm}}$ absorbance of $>0.2$. Seroconversion occurred when the $\mathrm{OD}_{450 \mathrm{~nm}}$ absorbance was greater than or equal to three times the value obtained at week 0 and the endpoint titre was greater than the assay LOD, which was 1:25.

\section{IFN $\gamma$ ELISPOT assay}

T cell responses against the Gag polyprotein were determined in rhesus macaque PBMCs by ELISPOT assay. Ninety-six-well Multiscreen Immobilon-P plates (Millipore) were coated overnight with mouse anti-human interferon $\gamma$ (IFN $\gamma$ ) antibody (BD Pharmingen) at $5 \mu \mathrm{g} \mathrm{ml}^{-1}$. The plates were then washed three times with DPBS containing $0.25 \%$ Tween-20 and blocked with R10 (RPMI supplemented with $10 \%$ FBS and $1 \%$ penicillin-streptomycin) at $37^{\circ} \mathrm{C}$ for $1 \mathrm{~h}$. SIVmac239-derived Gag peptides (JPT) were plated at a concentration of $1 \mu \mathrm{g}$ per well along with 200,000 rhesus macaque cells per well, and the cells and peptides were then incubated for $18-24$ h at $37^{\circ} \mathrm{C}$. All subsequent steps were performed at room temperature. The wells were washed nine times with the above wash buffer, cells were lysed with deionized water for $3 \mathrm{~min}$ and plates were then incubated with biotinylated rabbit anti-human IFN $\gamma$ antibody (U-Cytech) at a final concentration of $1 \mu \mathrm{g} \mathrm{ml}^{-1}$ for $2 \mathrm{~h}$. The wells were then incubated with streptavidin-alkaline phosphatase (Southern Biotech) at a final concentration of $2 \mu \mathrm{g} \mathrm{ml}^{-1}$ for $2 \mathrm{~h}$, washed five times with the above wash buffer and incubated with 5-bromo-4-chloro-3'-indolyphosphate $p$-toluidine salt (BCIP)/nitro-blue tetrazolium chloride (NBT) substrate solution (Thermo Scientific Pierce) for $7 \mathrm{~min}$. The spot-forming cell (SFC) units were sent to ZellNet Consulting for quantification. The mock-stimulated background-subtracted median values were reported, and the assay LOD was 5 SFCs per $10^{6}$ PBMCs.

\section{Intact proviral DNA assay}

An SHIV-adapted version of IPDA (SHIV-IPDA) was used to determine the number of intact SHIV proviruses. Total genomic DNA was extracted from unfractionated PBMCs using a QIAamp DNA Mini kit (Qiagen). DNA quality and quantity were evaluated by spectrophotometry and fluorometry, respectively, and SHIV-IPDA was then performed on the isolated DNA. An in-depth description of SHIV-IPDA will be included in an upcoming manuscript by E. Fray et al. In brief, SHIV-IPDA consists of a three-component multiplex droplet digital PCR (ddPCR) reaction. The first is a SHIV proviral discrimination reaction targeting two conserved, frequently deleted regions of the SHIV genome to determine the intact provirus count; the second is a two-long terminal repeat (2-LTR) DNA circle reaction to determine 2-LTR circle counts; and the third is a copy reference/DNA shearing reaction targeting ribonuclease $\mathrm{P} / \mathrm{MRP}$ subunit P30 (RPP30) to determine assay input cell equivalents and the DNA shearing index (DSI). All ddPCR reactions were performed using a Bio-Rad QX200 AutoDG ddPCR system with Bio-Rad ddPCR supermix for probes with no dUTP. After DSI correction and subtraction of intact 2-LTR circles, the intact proviral frequencies were reported per million input cells. The endpoint ddPCR data were collected using Bio-Rad QuantaSoft version 1.7.4.0917.

\section{Plasma virus genotypic analysis}

Total RNA was extracted from 50 - $\mu$ l plasma aliquots obtained from each viraemic monkey using the MagMAX-96 Viral RNA Isolation kit (Life Technologies) in conjunction with the Thermo Scientific KingFisher Flex automated extraction platform and were eluted in $60 \mu$ IVE buffer. The portion of gagencoding capsid in each sample was then individually amplifiedby RT-PCRusing aSuperScriptIV One-StepRT-PCRSystem(Life Technologies) according to the manufacturer's recommended protocol. Amplification of the SHIV capsid-encoding region in each sample was performed using primers SIV-CA-F (5'-CCAAAAACAAGTAGACCAACAG- ${ }^{\prime}$ ) and SIV-CA-R (5'-TGCAAAAGGGATTGGCAC-3'), and the products were subjected to population-level bulk sequencing at Elim Biopharmaceuticals using the same primer set. To identify codon changes, Sequencher version 4.9 (Gene Codes) was used to align DNA encoding sequences of the SHIV capsid for each sample with that of the parent virus obtained from each infected placebo-treated control animal. This provided a control for potential genetic drift that might have occurred during the 24-week efficacy study. 


\section{Statistical methods}

Protection against acquired infection was analysed using Cox proportional hazard regression models based on the exact partial likelihood for discrete time expressed in weeks, which explicitly accounts for the time-varying viral challenge dose in the model. The hazard ratios with $95 \%$ confidence intervals for per-exposure relative reductions in acquisition risk were calculated for the GS-CA1-treated groups, and the results were compared with those for the vehicle-treated control group. Comparisons were considered statistically significant at a two-sided alpha level of $0.05(P<0.05)$. Statistical analyses were performed using GraphPad Prism version 8.1.2, SAS version 9.4 and R Studio software version 4.0.5.

\section{Reporting summary}

Further information on research design is available in the Nature Research Reporting Summary linked to this paper.

\section{Data availability}

All relevant data are available in the Article. Any additional data are available from the corresponding authors upon reasonable request. Source data are provided with this paper.

22. Ramanathan, R. et al. It is time for a paradigm shift in drug discovery bioanalysis: from SRM to HRMS. J. Mass Spectrom. 46, 595-601 (2011).
23. Sturm, R. M., Jones, B. R., Mulvana, D. E. \& Lowes, S. HRMS using a Q-Exactive series mass spectrometer for regulated quantitative bioanalysis: how, when, and why to implement. Bioanalysis 8, 1709-1721 (2016).

Acknowledgements We thank E. Bondzie, O. Sanborn, D. Sellers and K. Verrington for assistance with rhesus specimen processing and S. Suthram for assistance with statistical analysis. The study was funded by Gilead Sciences.

Author contributions J.M. designed and executed the preclinical metabolism studies. D.H. performed and analysed the antiviral assays. K.W. performed and analysed the equilibrium dialysis shift assays. D.K. oversaw GS-CA1 synthesis. W.R. supported drug formulation. B.L., J.Z., S.R.Y. and W.R. designed and analysed the GS-CA1 dose-range-finding studies in rhesus macaques. S.J.V., E.B., A.C., S.R.Y. and D.H.B. oversaw rhesus efficacy study execution with input from C.C., W.B. and T.C., and R.G., S.J.V. and J.B. performed rhesus specimen processing S.J.V. and N.B.M. performed SHIV viral load measurements. H.W., T.A. and J.P.N. performed the Env ELISAs. S.P. performed the Gag ELISPOTs. W.J.R. and M.J.F. led the clinical care of the rhesus macaques. B.L., J.Z. and S.R.Y. analysed the plasma GS-CA1 concentrations. D.H. and S.R.Y. performed resistance analysis of the rhesus plasma virus. F.C. performed statistical analysis. S.J.V., E.B., R.G., S.R.Y. and D.H.B. interpreted the data and wrote the manuscript with input from all authors.

Competing interests E.B., D.H., B.L., K.W., J.M., W.R., F.C., J.Z., D.K., C.C., W.B., T.C., R.G. and S.R.Y. are employees of Gilead Sciences and received salary and stock ownership as compensation for their employment. The authors otherwise declare no potential conflicts of interest.

Additional information

Supplementary information The online version contains supplementary material available at https://doi.org/10.1038/s41586-021-04279-4.

Correspondence and requests for materials should be addressed to Stephen R. Yant or Dan H. Barouch.

Peer review information Nature thanks the anonymous reviewers for their contribution to the peer review of this work.

Reprints and permissions information is available at http://www.nature.com/reprints. 
Article

a

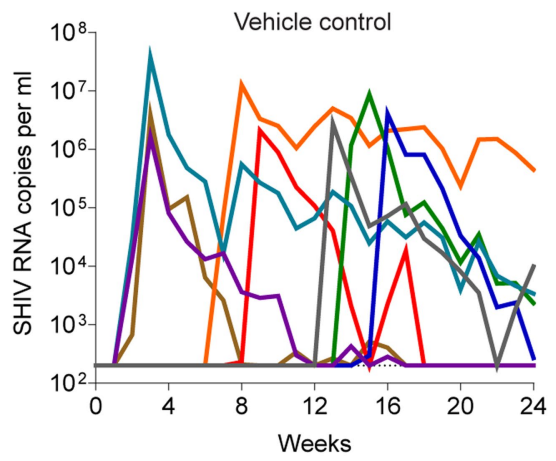

b

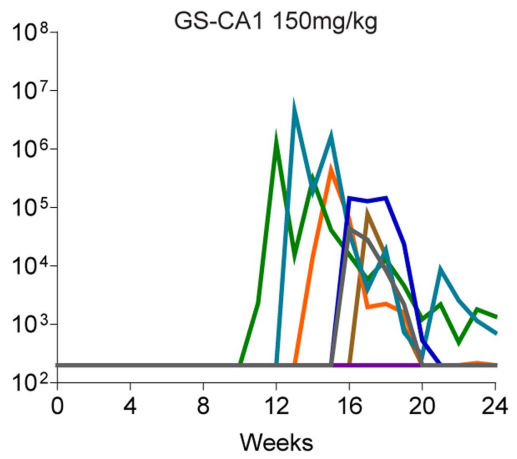

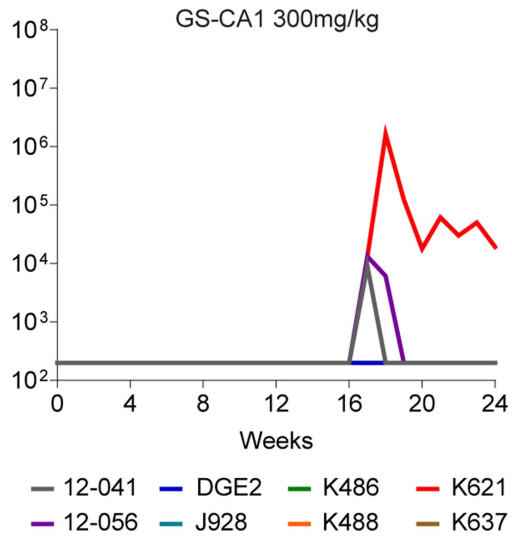

$-12-158-\mathrm{BC} 53-\mathrm{H} 71 \mathrm{~A}-\mathrm{K} 940$
$-12-172-\mathrm{BD} 74-\mathrm{K} 871-\mathrm{TM} 1$

$-12-077-\mathrm{K} 212$

$-\mathrm{K} 342-\mathrm{K} 653$

macaques $(n=8)$ treated with a single $150 \mathrm{mg} / \mathrm{kg}$ subcutaneous injection of

Extended Data Fig. 1 | Viral loads among vehicle- and GS-CA-1-treated animals during the SHIV challenge study. a, Plasma SHIV viral loads measured by gag RT-qPCR among vehicle control rhesus macaques $(n=8)$ through week 24 following 15 weekly intrarectal challenges. b, Same data as (a) among rhesus GS-CA1 at week 0.c, Same data as (a) and (b) among rhesus macaques $(n=8)$ treated with a single $300 \mathrm{mg} / \mathrm{kg}$ subcutaneous injection of GS-CA1 at week 0 . Dotted lines represent the assay LOD (200 copies per $\mathrm{ml}$ ). 
a

Peak viral load

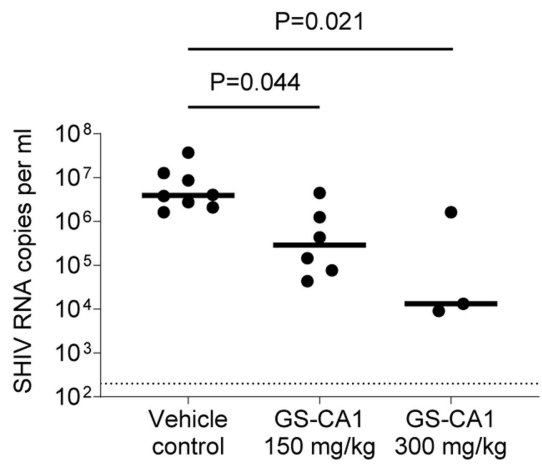

Extended Data Fig. 2 | Peak and setpoint SHIV viral loads among infected rhesus macaques treated with vehicle control or GS-CA1. a, Peak plasma SHIV viral loads measured by gag RT-qPCR among infected rhesus macaques treated with vehicle control $(n=8), G S-C A 1$ dosed at $150 \mathrm{mg} / \mathrm{kg}(\mathrm{n}=6)$, or b

7 wpi viral load

ns

ns

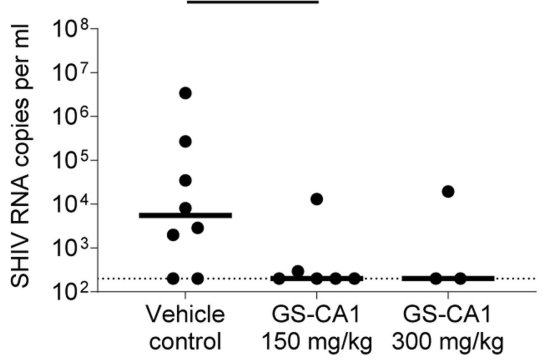

GS-CA1 dosed at $300 \mathrm{mg} / \mathrm{kg}(\mathrm{n}=3)$. b, Plasma SHIV viral loads 7 weeks post-infection (wpi) among the same groups as (a). Dotted lines represent the assay LOD (200 copies per $\mathrm{ml}$ ). Solid lines represent group medians. P values reflect Kruskal-Wallis tests. 


\section{Article}

a

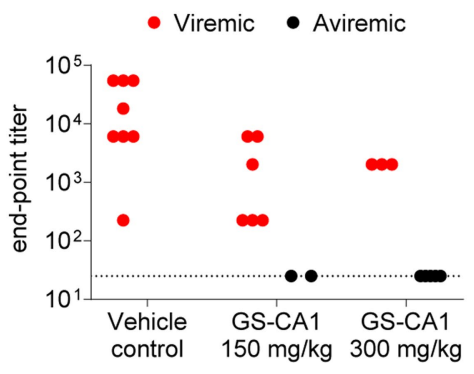

Extended Data Fig. 3 | GS-CA1-treated rhesus macaques that remain aviremic do not show immunologic evidence of SHIV infection. a, Week 24 anti-gp140 Env ELISA comparing viremic and aviremic animals in the vehicle control and GS-CA1 groups. Dotted line represents assay LOD (1:25 endpoint
- Viremic • Aviremic

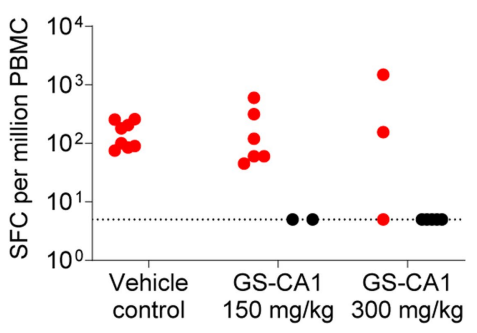

titer). b, Week 19 Gag ELISPOT comparing viremic and aviremic animals in the vehicle control and GS-CA1 groups. Data are represented as spot-forming cells (SFC) per $10^{6}$ PBMCs. Dotted line represents the assay LOD (5 SFC per million PBMCs). 


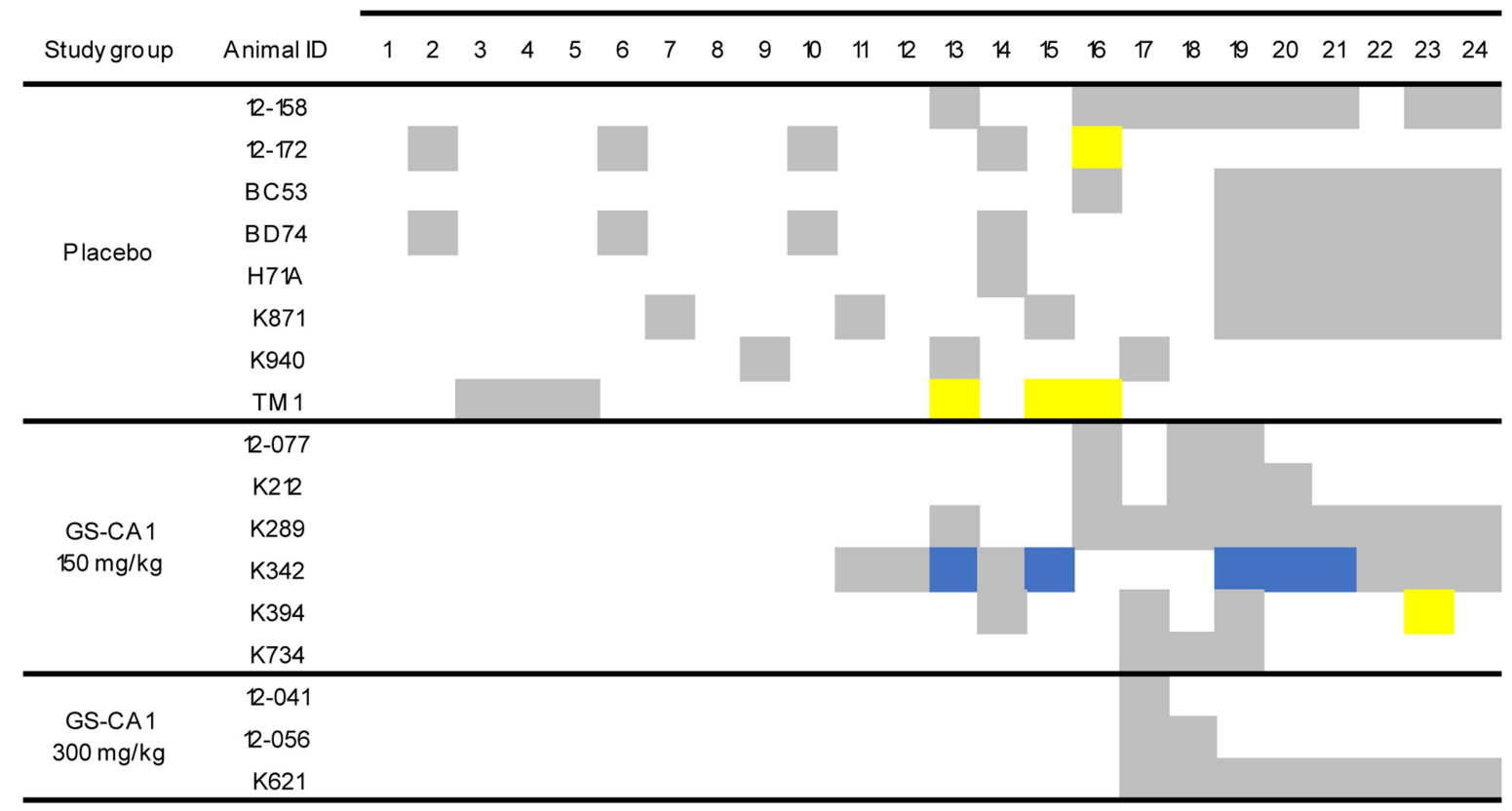

b

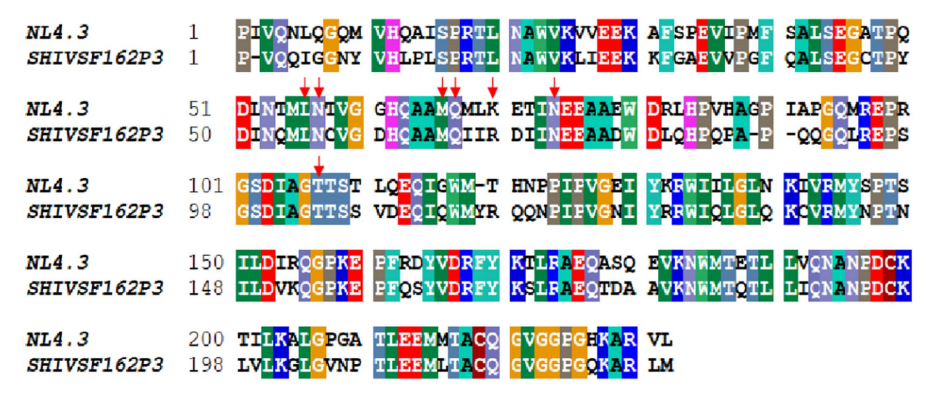

c

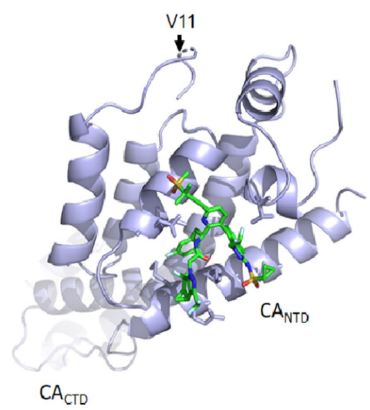

Extended data Fig. 4 | Sequence analysis of study-emergent CA mutations. a, Longitudinal CA sequence analysis of select plasma samples from viremic study animals. Samples with population-scale wild-type and V11A CA sequences are shaded grey and blue, respectively, whereas yellow boxes denote sequence failures. b, Alignment of HIV-1 (NL4.3 strain) and SHIV-SF162P3 CA amino-acid sequences. Shaded regions represent invariant residues, hashed lines denote sequence gaps, and red arrows highlight HIV-1 residues associated with GS-CA1 resistance (L56, N57, M66, Q67, K70, N74,
T107). c, A single CA monomer (rendered as ribbons in cyan) within the HIV-1CA hexamer-LEN crystal structure ${ }^{16}$, with notation of the CAN-terminal and C-terminal domains ( $\mathrm{CA}_{\mathrm{NTD}}$ and $\mathrm{CA}_{\mathrm{CTD}}$, respectively) and a GS-CA1 molecule (carbon atoms shown as green) docked at the LEN binding site. Location of the only CA variant (V11A) transiently detected by bulk sequencing is shown relative to all HIV-1CA residues associated with bona fide in vitro GS-CA1 and LEN resistance (highlighted as sticks). 


\section{Article}

Extended Data Table 1 | Comparison of the major structural and functional attributes for small molecule capsid inhibitors LEN and GS-CA1
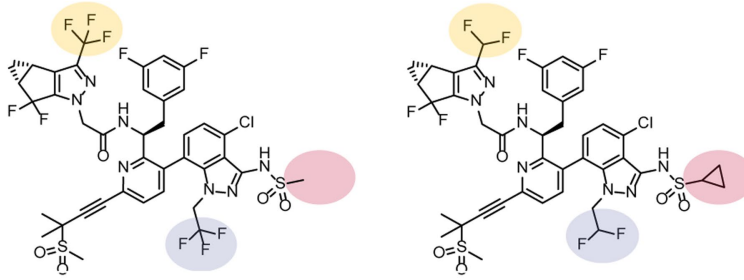

Parameter

Analysis

LEN $^{\mathrm{a}}$

GS-CA $1^{b}$

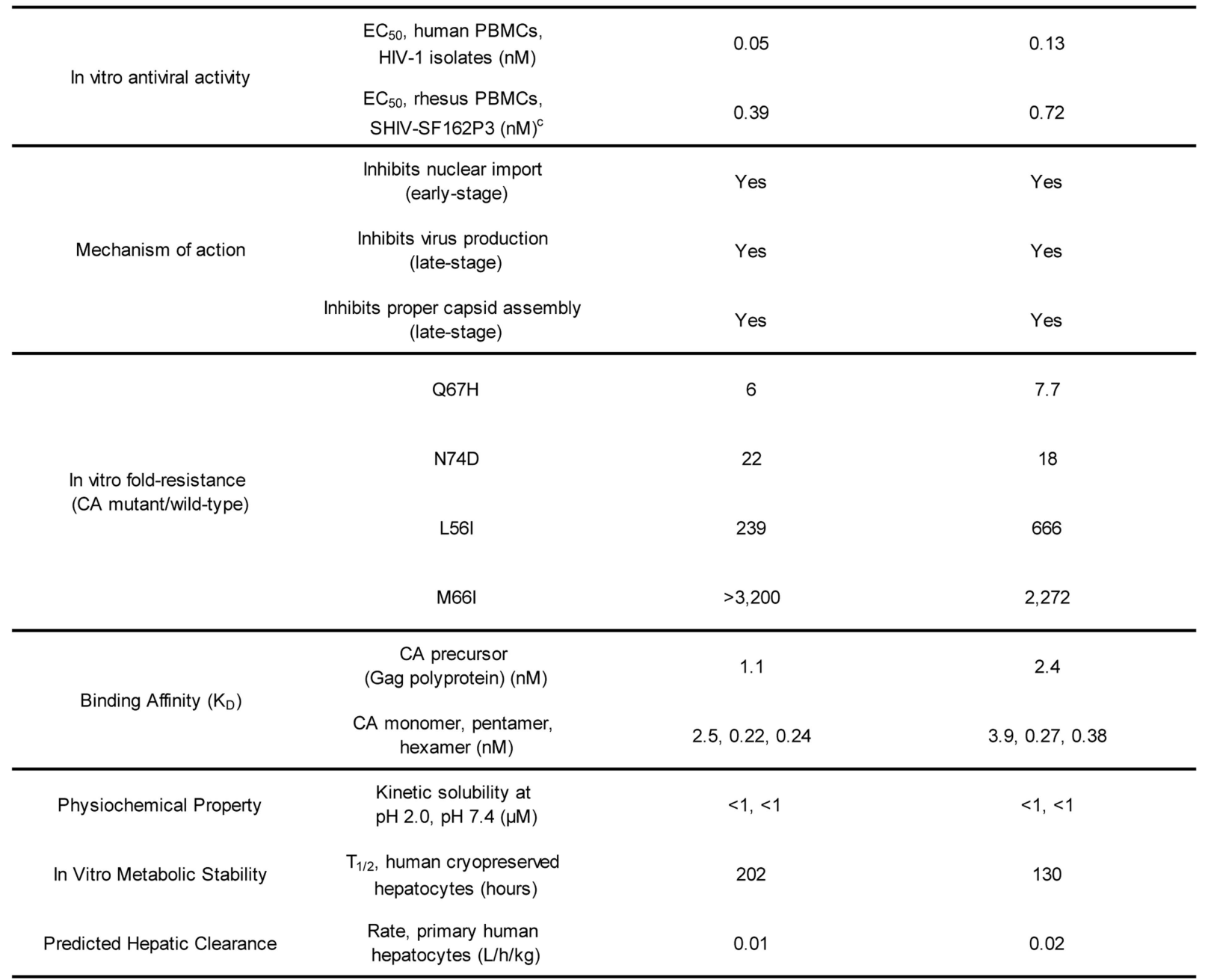

a, Link et al, Nature, 2020; ${ }^{16}$ b, Yant et al, Nat.Med, $2019 ;{ }^{4} \mathrm{c}$, this report. Colored regions highlight structural distinctions between these long-acting capsid inhibitors. 
Extended Data Table 2 | Determination of the GS-CA1 rhesus paEC $_{95}$ in rhesus PMBCs

\begin{tabular}{ccccc} 
Compound & $\begin{array}{c}\text { Rhesus PBMC } \\
\mathrm{EC}_{50}(\mathrm{nM})\end{array}$ & $\begin{array}{c}\text { Rhesus PBMC } \\
\mathrm{EC}_{95}(\mathrm{nM})\end{array}$ & $\begin{array}{c}\text { Rhesus EQD } \\
\text { plasma shift }\end{array}$ & $\begin{array}{c}\text { Rhesus PBMC } \\
\text { paEC } 95(\mathrm{nM})\end{array}$ \\
\hline GS-CA1 & $0.72 \pm 0.11$ & $1.91 \pm 0.16$ & 15.8 & $30.2 \pm 2.5$ \\
\hline
\end{tabular}

The GS-CA1 $\mathrm{EC}_{50}$ against SHIV-SF162P3 in rhesus PMBCs calculated from dose-response curves, the estimated $\mathrm{EC}_{95}$ based on the Hill slope value against the HIV-1 IIIb strain in MT-4 cells, and the rhesus protein adjusted $\mathrm{EC}_{95}\left(\mathrm{paEC}_{95}\right)$ based on competitive equilibrium dialysis (EQD) plasma shift assays. $E_{50}$ data (mean \pm s.d.) are from 7 independent assays $(n=3$ biological replicates each). EQD data are mean values from three independent experiments performed in singlet. 


\section{Article}

Extended Data Table 3| Pharmacokinetic parameters following a single subcutaneous administration of GS-CA1 in rhesus macaques

\begin{tabular}{|c|c|c|c|c|}
\hline \multirow{2}{*}{$\begin{array}{l}\text { Pharmacokinetic } \\
\text { parameter }\end{array}$} & \multicolumn{2}{|c|}{ GS-CA1 $150 \mathrm{mg} / \mathrm{kg}(\mathrm{n}=8)$} & \multicolumn{2}{|c|}{ GS-CA1 $300 \mathrm{mg} / \mathrm{kg}(\mathrm{n}=8)$} \\
\hline & Mean $\pm S D$ & CV\% & Mean \pm SD & CV\% \\
\hline $\mathrm{AUC}_{\text {last }}(\mu \mathrm{M} \cdot \mathrm{h})$ & $959 \pm 435$ & 45 & $2040 \pm 722$ & 35 \\
\hline $\mathrm{AUC}_{\text {inf }}(\mu \mathrm{M} \cdot \mathrm{h})$ & $960 \pm 435$ & 45 & $2044 \pm 722$ & 35 \\
\hline$t_{1 / 2}(h)$ & $317 \pm 132$ & 42 & $287 \pm 45$ & 16 \\
\hline $\mathrm{C}_{\max }(\mu \mathrm{M})$ & $3.02 \pm 1.07$ & 35 & $5.53 \pm 1.47$ & 27 \\
\hline $\mathrm{T}_{\max }(\mathrm{h})$ & $24.0 \pm 0.0$ & 0 & $42.0 \pm 50.9$ & 121 \\
\hline
\end{tabular}

Pharmacokinetic parameters, including area under the plasma concentration-time curve from time 0 to the last quantifiable time point $\left(\mathrm{AUC}_{\text {last}}\right.$ ), area under the plasma concentration-time curve from time $O$ to infinity $\left(A \cup C_{\text {inf }}\right)$, maximal concentration $\left(C_{\max }\right)$, time to reach observed peak plasma concentration $\left(T_{\max }\right)$, and terminal half-life $\left(t_{1 / 2}\right)$ determined by non-compartmental analysis using Phoenix WinNonlin 6.4 build 8.1.0.3530. CV, coefficient of variation (100 X standard deviation / mean). 
Extended Data Table 4 | Detection of intact proviral SHIV DNA relative to viremia in the challenge study

\begin{tabular}{|c|c|c|c|c|c|c|c|c|}
\hline \multirow[b]{2}{*}{$\begin{array}{l}\text { Treatment } \\
\text { group }\end{array}$} & \multirow[b]{2}{*}{$\begin{array}{c}\text { Rhesus } \\
\text { macaque } \\
\text { ID }\end{array}$} & \multirow[b]{2}{*}{$\begin{array}{l}\text { Study } \\
\text { week }\end{array}$} & \multirow[b]{2}{*}{$\begin{array}{l}\text { Plasma } \\
\text { viral load }\end{array}$} & \multicolumn{5}{|c|}{ IPDA count per million PBMC } \\
\hline & & & & $\begin{array}{c}\text { Intact } \\
\text { proviruses }\end{array}$ & $\begin{array}{l}5 \text { ' defective } \\
\text { proviruses }\end{array}$ & $\begin{array}{l}3^{\prime} \text { defective } \\
\text { proviruses }\end{array}$ & $\begin{array}{c}\text { Total } \\
\text { viruses }\end{array}$ & $\begin{array}{l}2 \text { LTR } \\
\text { circles }\end{array}$ \\
\hline \multirow{6}{*}{$\begin{array}{l}\text { Vehicle } \\
\text { control }\end{array}$} & K940 & 7 & $<200$ & 0.00 & 0.00 & 0.00 & 0.00 & 0.00 \\
\hline & K940 & 8 & 229 & 7.56 & 0.00 & 0.00 & 7.56 & 0.00 \\
\hline & K871 & 6 & $<200$ & 0.00 & 0.00 & 0.00 & 0.00 & 0.00 \\
\hline & K871 & 7 & 76022 & 458.42 & 302.03 & 13.89 & 774.34 & 15.53 \\
\hline & $\mathrm{TM} 1$ & 1 & $<200$ & 0.00 & 4.31 & 4.31 & 8.61 & 0.00 \\
\hline & TM1 & 2 & 670 & 4.88 & 3.96 & 1.01 & 9.85 & 0.00 \\
\hline \multirow{7}{*}{$\begin{array}{c}\text { GS-CA1 } \\
150 \mathrm{mg} / \mathrm{kg}\end{array}$} & $\mathrm{K} 212$ & 15 & $<200$ & 0.00 & 0.00 & 0.00 & 0.00 & 0.00 \\
\hline & $\mathrm{K} 212$ & 16 & 144532 & 1424.75 & 610.36 & 0.00 & 2035.12 & 25.51 \\
\hline & K394 & 12 & $<200$ & 0.00 & 0.00 & 0.00 & 0.00 & 0.00 \\
\hline & K394 & 13 & $<200$ & 3.07 & 0.00 & 0.00 & 3.07 & 0.00 \\
\hline & K394 & 14 & 14481 & 21.35 & 21.59 & 2.98 & 45.92 & 0.00 \\
\hline & K734 & 16 & $<200$ & 0.00 & 0.00 & 0.00 & 0.00 & 0.00 \\
\hline & K734 & 17 & 76901 & 455.05 & 285.21 & 0.00 & 740.26 & 9.53 \\
\hline \multirow{2}{*}{$\begin{array}{c}\text { GS-CA1 } \\
300 \text { mg/kg }\end{array}$} & $12-056$ & 16 & $<200$ & 0.00 & 0.00 & 0.00 & 0.00 & 0.00 \\
\hline & $12-056$ & 17 & 13193 & 82.48 & 38.41 & 0.00 & 120.89 & 1.48 \\
\hline
\end{tabular}

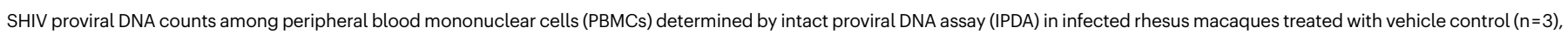

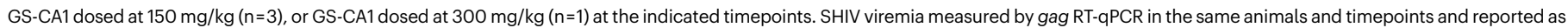
SHIV RNA copies per ml. 


\section{Article}

Extended Data Table 5 | Time from onset of viremia to seroconversion among infected rhesus macaques treated with vehicle control or GS-CA1

\begin{tabular}{|c|c|c|c|c|}
\hline $\begin{array}{l}\text { Treatment } \\
\text { group }\end{array}$ & $\begin{array}{c}\text { Rhesus } \\
\text { macaque } \\
\text { ID }\end{array}$ & $\begin{array}{c}\text { First viremic } \\
\text { timepoint } \\
\text { (study week) }\end{array}$ & $\begin{array}{c}\text { Seroconversion } \\
\text { timepoint } \\
\text { (study week) }\end{array}$ & $\begin{array}{l}\text { First viremia to } \\
\text { seroconversion } \\
\text { interval (weeks) }\end{array}$ \\
\hline \multirow{8}{*}{$\begin{array}{l}\text { Vehicle } \\
\text { control }\end{array}$} & $12-158$ & 13 & 14 & 1 \\
\hline & $12-172$ & 2 & 4 & 2 \\
\hline & BC53 & 15 & 17 & 2 \\
\hline & BD74 & 2 & 4 & 2 \\
\hline & $\mathrm{H} 71 \mathrm{~A}$ & 14 & 18 & 4 \\
\hline & K871 & 7 & 20 & 13 \\
\hline & K940 & 8 & 11 & 3 \\
\hline & TM1 & 2 & 6 & 4 \\
\hline \multirow{6}{*}{$\begin{array}{c}\text { GS-CA1 } \\
150 \mathrm{mg} / \mathrm{kg}\end{array}$} & $12-077$ & 16 & 17 & 1 \\
\hline & K212 & 16 & 20 & 4 \\
\hline & K289 & 13 & 18 & 5 \\
\hline & K342 & 11 & 16 & 5 \\
\hline & K394 & 14 & 19 & 5 \\
\hline & K734 & 17 & 21 & 4 \\
\hline \multirow{3}{*}{$\begin{array}{c}\text { GS-CA1 } \\
300 \mathrm{mg} / \mathrm{kg}\end{array}$} & $12-041$ & 17 & 18 & 1 \\
\hline & $12-056$ & 17 & 18 & 1 \\
\hline & K621 & 17 & 20 & 3 \\
\hline
\end{tabular}

Onset of plasma SHIV viremia measured by gag RT-qPCR in the three study groups. Seroconversion timepoints determined by serum Env ELISA among infected animals in the three groups. 


\section{Reporting Summary}

Nature Portfolio wishes to improve the reproducibility of the work that we publish. This form provides structure for consistency and transparency in reporting. For further information on Nature Portfolio policies, see our Editorial Policies and the Editorial Policy Checklist.

\section{Statistics}

For all statistical analyses, confirm that the following items are present in the figure legend, table legend, main text, or Methods section.

$\mathrm{n} / \mathrm{a} \mid$ Confirmed

$\bigotimes$ The exact sample size $(n)$ for each experimental group/condition, given as a discrete number and unit of measurement

$\square$ A statement on whether measurements were taken from distinct samples or whether the same sample was measured repeatedly

The statistical test(s) used AND whether they are one- or two-sided

Only common tests should be described solely by name; describe more complex techniques in the Methods section.

Х $\square$ A description of all covariates tested

Х $\square$ A description of any assumptions or corrections, such as tests of normality and adjustment for multiple comparisons

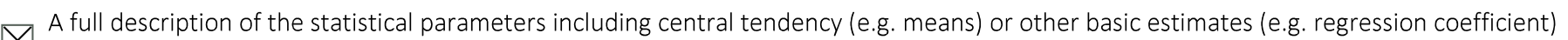

AND variation (e.g. standard deviation) or associated estimates of uncertainty (e.g. confidence intervals)

For null hypothesis testing, the test statistic (e.g. $F, t, r$ ) with confidence intervals, effect sizes, degrees of freedom and $P$ value noted Give $P$ values as exact values whenever suitable.

Х $\square$ For Bayesian analysis, information on the choice of priors and Markov chain Monte Carlo settings

Х $\square$ For hierarchical and complex designs, identification of the appropriate level for tests and full reporting of outcomes

$\triangle(\square$ Estimates of effect sizes (e.g. Cohen's $d$, Pearson's $r$ ), indicating how they were calculated

\section{Our web collection on statistics for biologists contains articles on many of the points above.}

\section{Software and code}

Policy information about availability of computer code

Data collection SoftMax Pro 6.3.1 was used to acquire SIV p27 ELISA data.

Thermo Scientific Xcalibur 4.0.27.19 was used to collect LC/MS data.

Viral load data were collected using the Quantstudio version 6 Flex Real-Time PCR System (Applied Biosystems).

Endpoint droplet digital PCR data were collected using Bio-Rad QuantaSoft version 1.7.4.0917.

Data analysis

XLfit 5.5.0.5 software (IDBS) was used to analyze SIV p27 ELISA data and plot data for antiviral dose response curves.

Analyst 1.6.1 software was used to analyze LC/MS-MS equilibrium dialysis shift data.

Dionex (Thermo Scientific) Chromeleon 6.8 software was used to analyze radiochromatographic peak area data for [3H] GS-CA1 and its metabolites.

GraphPad Prism version 8.1.2 was used to prepare Kaplan-Meier animal infection rate plots, with Cox regression analysis performed using SAS version 9.4 and R Studio version 4.0 softwares.

Thermo Scientific Xcalibur 4.0.27.19 was used to analyze LC/MS and high-resolution mass spectrometry data for plasma GS-CA1 levels. Phoenix WinNonlin 6.4 build 8.1.0.3530 was used for noncompartmental analyses of pharmacokinetic (PK) parameters.

SHIV capsid coding region sequencing analysis used Sequencher version 4.9. 
Policy information about availability of data

All manuscripts must include a data availability statement. This statement should provide the following information, where applicable:

- Accession codes, unique identifiers, or web links for publicly available datasets

- A description of any restrictions on data availability

- For clinical datasets or third party data, please ensure that the statement adheres to our policy

All relevant data are available in the article. Any additional data are available from the corresponding authors upon reasonable request. Source data are provided with this paper.

\section{Field-specific reporting}

Please select the one below that is the best fit for your research. If you are not sure, read the appropriate sections before making your selection.

$\bigotimes$ Life sciences $\quad \square$ Behavioural \& social sciences $\quad \square$ Ecological, evolutionary \& environmental sciences

For a reference copy of the document with all sections, see nature.com/documents/nr-reporting-summary-flat.pdf

\section{Life sciences study design}

All studies must disclose on these points even when the disclosure is negative.

Sample size We did not rely on statistical analyses to determine sample size since we could not estimate a priori the level of protection which may be afforded by a long acting capsid inhibitor, a new class of HIV antiviral. However, we modeled our design after repeat challenge non-human primate studies previously conducted by us and other groups evaluating other classes of HIV antivirals for pre-exposure and post-exposure prophylaxis.

Data exclusions No data were excluded.

Replication Virologic and immunologic measures were performed in duplicate. Technical replicates were minimally different. All attempts at replication were successful.

Randomization Animals were balanced for age and gender and otherwise randomly allocated to groups.

Blinding All immunologic and virologic assays were performed blinded.

\section{Reporting for specific materials, systems and methods}

We require information from authors about some types of materials, experimental systems and methods used in many studies. Here, indicate whether each material, system or method listed is relevant to your study. If you are not sure if a list item applies to your research, read the appropriate section before selecting a response.

\begin{tabular}{l|l} 
Materials \& experimental systems \\
\hline$n / a$ & Involved in the study \\
\hline & $\bigotimes$ Antibodies \\
$\square$ & $\square$ Eukaryotic cell lines \\
$\square$ & $\square$ Palaeontology and archaeology \\
$\square$ & $\bigotimes$ Animals and other organisms \\
$\square$ & $\square$ Human research participants \\
$\searrow$ & $\square$ Clinical data \\
$\searrow$ & $\square$ Dual use research of concern
\end{tabular}

\begin{tabular}{l|l} 
Methods \\
\hline n/a & Involved in the study \\
$\square$ & $\square$ ChIP-seq \\
$\searrow$ & $\square$ Flow cytometry \\
$\searrow$ & $\square$ MRI-based neuroimaging
\end{tabular}

\section{Antibodies}

Antibodies used

For evaluation of the GS-CAI EC50 against SHIV-SF162P3 in rhesus macaque PBMCs, SIV p27 antigen capture ELISA assay (Advanced Bioscience Laboratories, catalog number 5436) was used. For detection of rhesus macaque humoral responses to SHIV-SF162P3 Env, ELISA was used with horseradish peroxidase (HRP)-conjugated goat anti-human secondary antibody (Jackson ImmunoResearch Laboratories, catalog number 109-035-003). For detection of rhesus macaque cellular responses to SHIV-SF162P3 Gag, ELISPOT was used with mouse anti-human IFN- $y$ antibody (BD Pharmingen, catalog number 554699) and biotinylated rabbit anti-human IFN-y (U CyTech biosciences, catalog number CT243). 


\section{Animals and other organisms}

Policy information about studies involving animals; ARRIVE guidelines recommended for reporting animal research

\begin{tabular}{|c|c|}
\hline Laboratory animals & 24 outbred Indian-origin male and female rhesus macaques (Macaca mulatta), 3-6 years old \\
\hline Wild animals & None \\
\hline Field-collected samples & None \\
\hline Ethics oversight & All studies were performed in accordance with the Covance and Alpha Genesis Inc. Institutional Animal Care and Use Committees \\
\hline
\end{tabular}

Note that full information on the approval of the study protocol must also be provided in the manuscript. 